\title{
INDUCTION OF RESIDUAL STRESSES AND INCREASE OF SURFACE HARDNESS BY MACHINE HAMMER PEENING TECHNOLOGY
}

\author{
ADJASSOHO, B[eatrix]; KOZESCHNIK, E[rnst]; LECHNER, C[hristoph]; \\ BLEICHER, F[riedrich]; GOESSINGER, S[tefan] \& BAUER, C[hristian]
}

\begin{abstract}
Machine Hammer Peening is a novel technology for surface treatment, which is based on an actuator that can be attached to any kind of machine tool. This actuator moves an axially guided hard metal ball with an oscillating movement to a work piece surface. The main positive effects of the treatment are the induction of compressive residual stresses, the hardness increase of the upper surface layer and a reduction of surface roughness. Also, a controlled and defined structuring of a material surface is possible by the use of this technology. The purpose of this paper is to show, how this novel technology can be used to influence the surface and the upper surface layer of a material for compressive residual stresses and surface hardening. The X-ray diffraction method and the hole drilling method were used to measure the residual stresses. A comparison of both investigation results is done as part of this work. The results of all investigations show a hardness increase of the upper surface layer.
\end{abstract}

Keywords: Machine Hammer Preening, residual stress, hardness increase

\section{INTRODUCTION}

Machine Hammer Preening (MHP) - developed in Germany - is a novel surface treatment technology. With this method, the work piece surface is modified through repeated impacts by a spherical carbide tool through oscillating movement. The MHP actuator can be mounted in conventionally machining centers. In order to conduct research in this technological field, an interdisciplinary project at the Vienna University of Technology, Austria was established. Three Institutes together with eleven company partners and the Austrian Excellence Centre for Tribology are working in this field to support this novel Technology with scientific research.

The method of surface modification with MHP is a promising and powerful technological option in the field of production engineering. The three main pillars (see "Fig. 1") of this technology are as follows: induction of residual stresses, hardness increase in the upper surface layer and surface polishing [1] and [2]. The possible results in these three pillars mainly depend on the MHP machining parameters and also on the behaviour of the treated material. In this paper, the structural steel C45E (1.1191) is used for detailed research. However, the three mentioned pillars cannot be considered separately. There is always a close interaction between them and they are dependent on each other. For example, if the system should be used to induce residual stresses in a metal surface, there is also an impact on the surface topography and as well vice versa. This paper is mainly dealing with the results and findings of the first two pillars - induction of compressive residual stresses and hardness increase.
Investigations on the topic surface polishing are reported in other publications [2]-[5].

According to the inventor of this technology, accurapuls, Machine Hammer Peening is well placed to induce compressive residual stresses into the work piece surface, which are known to be highly beneficial to fatigue resistance. Moreover, the advantages of generating compressive residual stresses in metal surfaces could be the reduction of tensile stresses in the surface layer, lower risk of stress corrosion cracking or prevention of crack formation and deceleration of crack growth [1].

Facing the fact that this technology is rather new, few scientific research was made so far in the topic of induction of residual stress caused by MHP. In reference [3], some considerations and investigations can be found. The investigated materials in these studies were cold work steel ("Caldie") and cast material ("GGG 70L"). The investigations performed as in [2] are basis of the present experimental work, which builds upon these findings. The material C45E (1.1191) considered in the present paper has not been part of the previous investigations.

To produce the Machine Hammer Peened specimens for investigations, an electromagnetic Machine Hammer Penning system, which is distributed from the company accurapuls [1], was used. An overview how Machine Hammer Peening can be classified in comparison to other comparable surface treatment technologies is given in[2].

\section{THE MACHINE HAMMER PEENING TECHNOLOGY}

The actuator of the Machine Hammer Peening system can be mounted in nearly every machining centre. Therefore, 3-dimensional surfaces can be modified with this technology. The machining centre and the MHP actuator interact over specially designed CAM software developed by the inventor of the system and provided with every MHP actuator tool [1].

The schematic assembly of the Machine Hammer Peening actuator is shown in "Fig.2". The moving coil is based between an electromagnet and generates a force the so called Lorenz force - due to its current flow. The effective direction of this force is orientated in the direction of the coil. Furthermore, this Lorenz force is proportional to the induced current. By inversion of the direction of the current flow in the electromagnetic coil, the force is changing its direction. By applying an 
alternating voltage to the coil, this system is generating an oscillating movement of a plunger with a hard metal ball at its end [1] and [2].

There are several process parameters, which influence the behaviour of the MHP plunger at the interaction on the work piece surface. With these parameters, the impact force of the plunger tip on the surface can be varied, for example. The adjustable process parameters are listed in Tab.1. The illustration of these parameters can be seen in "Fig. 2".

For example, there are different kinds of diameters of the spherical plunger tip available, from a minimum diameter of $3 \mathrm{~mm}$ up to a maximum diameter of $20 \mathrm{~mm}$. Also, the other parameters can be chosen in a wide range and, therefore, they can have manifold influences for specific application fields. To investigate how different parameters impact the results of the MHP process, the following investigation procedures were defined.

\section{INVESTIGATION PROCEDURES}

The two main topics in this paper are the induction of residual stress and hardening of the upper surface layer of metal surfaces. An overview of the investigated topics and the measuring methods, which were used to evaluate the effect of the Machine Hammer Peening technology in interaction with the metal work pieces, are presented in "

Fig.3".

For the current research work, two different measuring methods for determining residual stresses on hammer peened surfaces in comparison to untreated ones were used: X-Ray diffraction and the hole drilling method. An overview about these measuring approaches and the experimental setups is given in chapter4. . A comparison of the results of both methods is summarized in "Fig. 8".

\begin{tabular}{|c|c|c|}
\hline $\begin{array}{c}\text { Process } \\
\text { parameter }\end{array}$ & Unit & Description \\
\cline { 2 - 3 } Diameter D & {$[\mathrm{mm}]$} & $\begin{array}{c}\text { Explanation } \\
\text { diameter of the spherical plunger } \\
\text { tip }\end{array}$ \\
\hline Distance t & {$[\mathrm{mm}]$} & $\begin{array}{c}\text { distance between surface and } \\
\text { plunger tip }\end{array}$ \\
\hline Line pitch s & {$[\mathrm{mm}]$} & $\begin{array}{c}\text { distance between two MHP tool } \\
\text { paths }\end{array}$ \\
\hline Frequency F & {$[\mathrm{Hz}]$} & $\begin{array}{c}\text { frequency of the oscillating } \\
\text { movement }\end{array}$ \\
\hline Feed rate v & {$[\mathrm{mm} / \mathrm{min}]$} & provided by the machine tool \\
\hline
\end{tabular}

Tab.1. Adjustable MHP process parameters [2]

In addition to the induction of residual stresses, MHP is also suitable to harden the surface layer of a metallic work piece. Investigations in this direction were also performed on the material C45E (1.1191) and other materials. To test the hardness increase on the upper surface layer, the ultrasonic contact impedance (UCI) method was used.

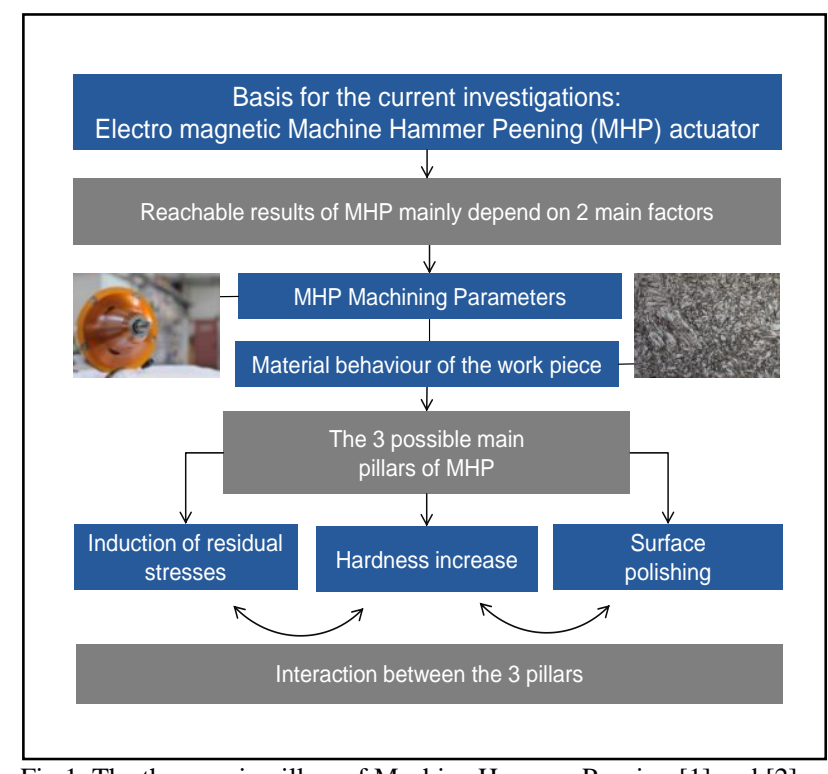

Fig.1. The three main pillars of Machine Hammer Peening [1] and [2]

\section{INDUCTION OF RESIDUAL STRESSES}

Machined peening is a process, which leads to a strong elasto-plastic interaction between the peening material and the work piece. During MHP, a transformation of kinetic energy into elastic and plastic deformation of the work material occurs, with its strongly depending on the radius of sphere and impact velocity rate. The residual compressive stresses in the course of hammer peening are a result of the locally occurring plastic deformation on the surface of the work piece and below. The amount of stress introduced by a single impact can be understood by the concept of Hertz 'compression as shown in "Fig. 4". In the Hertz 'compression process, after a sphere impact, the maximum plastic deformation occurs below the sample surface, which is also the location of the maximum residual compressive stresses[6].

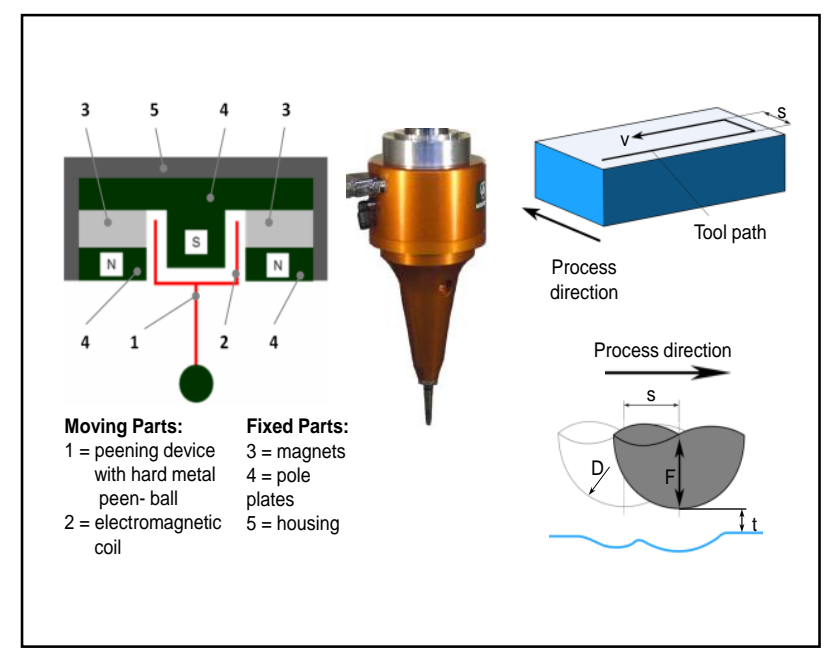

Fig.2. Machine Hammer Peening: Schematic layout, electromagnetic actuator, process parameters [1] and [2] 


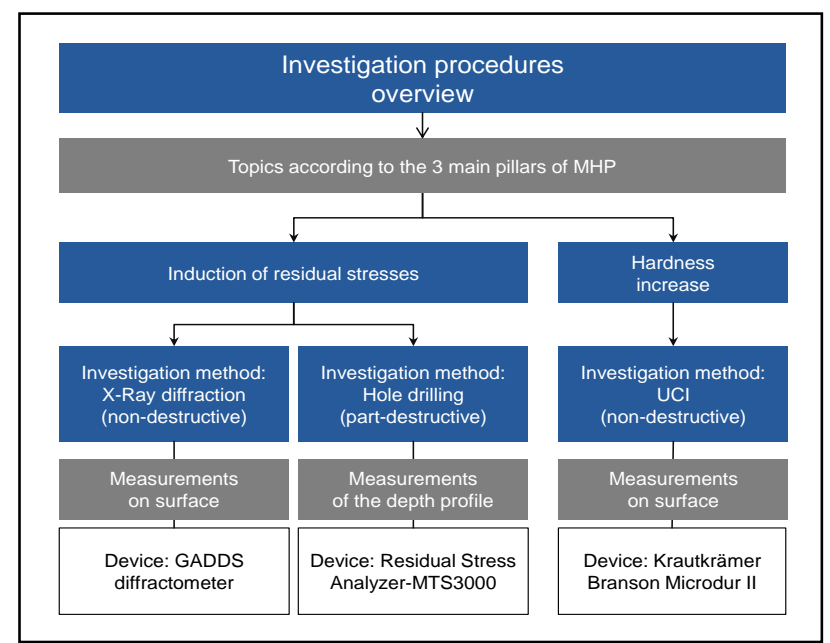

Fig.3. Investigated topics and measurement methods used in this work

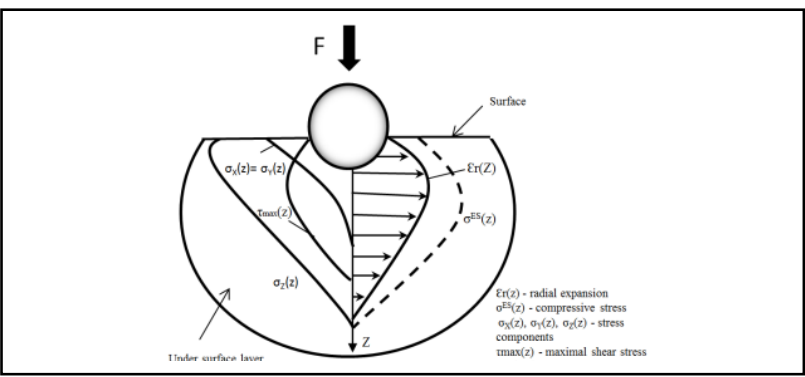

Fig. 4. Residual compression stress formation during at single spherical hammer impact [6]

\subsection{Measuring Methods}

To determine the amount of residual stresses induced in the peened surface layer during the MHP-Process, two different methods were applied(non-destructive and partially-destructive). The X-Ray diffraction method was used in order to detect the residual micro-stresses at the surface. The hole-drilling method was used to determine the residual macro-stresses as a function of distance to surface [7] and [8].

\section{$X$-ray diffraction method}

The X-ray diffraction method (XRD)method is a nondestructive investigation procedure, which is based on the principle of measuring the lattice spacing to identify the residual stresses in the material. If a tensile stress is applied to a material, the lattice spacing increases for planes perpendicular to the stress. It decreases for compressive stresses [7].

The XRD sin-square-psi method residual stress determination was performed by measuring the angles with the maximum diffraction intensity. The diffraction angle, 2 $\theta$, is recorded and, then, the lattice $d$-spacing is calculated from the diffraction angle, and the known Xray wavelength using Bragg's Law[7] and [8].

$$
\mathrm{n} \lambda=2 \mathrm{~d} \sin \Theta
$$

For the investigations, a GADDS diffract meter "Fig. 5",was used with a Vantec 2000 Bruker AXS X-Ray device using $\mathrm{Cu} \mathrm{K} \alpha_{1}$ radiation. The irradiated area was 1 $\mathrm{mm}$. The diffraction peaks arising from the Fe $\{211\}$ planes were measured between $80^{\circ}<2 \theta<85^{\circ} .17$ scans were performed for each stress measurement using different $\Psi$ values within the range $-60^{\circ} \leq \Psi \leq+60^{\circ}$ ( $\Psi$ different X-Ray beam angles to the surface). For evaluation of the result, the Rayflex Software was used with Lorentz Correction, Polarization and Background(linear) and the center of gravity method. All 17 scans were used to calculate the curve fit in the sinsquare-psi plots.

\section{Hole-drilling method}

The hole-drilling method is a strain gage based technique for determining residual stresses. This method is based on measuring the change of surface strain caused

\begin{tabular}{|l|l|}
\hline & Specimens \\
\cline { 2 - 2 } Material & $\begin{array}{l}\text { C45E } \\
(1.1191)\end{array}$ \\
\hline Pre processing before MHP & Milled \\
\hline MHP Diameter D [mm] & 8 \\
\hline MHP Distance t [mm] & 0,3 bis 1,2 \\
\hline MHP Line pitch s [mm] & 0,2 \\
\hline MHP Feed rate v [mm/min] & 2400 \\
\hline
\end{tabular}

Tab. 2. MHP parameters

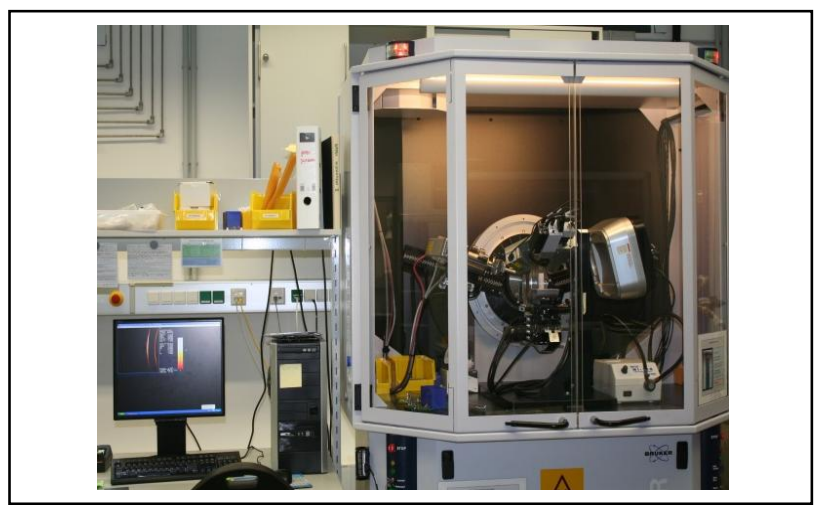

Fig. 5. Detector Vantec 2000 Bruker AXS

by stress relieving when drilling a shallow hole to a depth of approximately the hole diameter into a body with residual stresses [9].

The removal of stressed material results in a new stress state to achieves mechanical equilibrium. Therefore, the residual stress distribution near the location of the hole can be determined from the measured strain utilizing the theory of linear elasticity [9].

In the present work, the high speed drilling method was applied, which has the advantage that, due to the high rotating velocity of the milling cutter, no additional residual stresses are induced during drilling. This drilling method was performed with the system RESTANMTS3000 from SINT technologies „Fig. 6”.

For the strain measurements, strain gage rosettes of the type HBM-1.5/120RY61S were mounted on the surface of the specimens.

A milling cutter with a diameter of $1,6 \mathrm{~mm}$ was used to drill a hole in the centre of the strain gage rosette. Therefore, a diameter of the hole of $1,755 \mathrm{~mm}$ could be achieved. The procedure was performed in 20 milling 
steps of approximately $0.05 \mathrm{~mm}$ each [9]. The measurements were evaluated with the software provided by SINT technologies, using the Kockelmann calculation method.

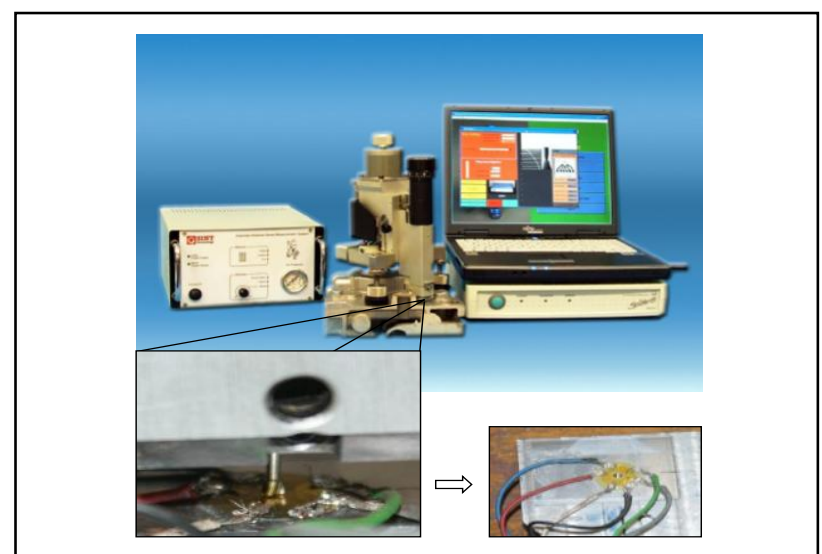

Fig. 6.Automatic system for measurement of residual stresses by the hole-drilling strain gage method MTS3000 [11]

\subsection{Experimental work}

For residual stress investigations, three specimens (A, $\mathrm{B}, \mathrm{C})$ of the material C45E (1.1191) have been prepared with MHP.

An overview about the treatments of these specimens is given in Tab. 3. Before these samples were modified with the Machine Hammer Peening system, 2 different kind of pre-processing steps were done. Specimen A was normalized - to reduce residual stresses of the work piece - specimens $\mathrm{B}$ and $\mathrm{C}$ were face milled before the MHP process. Both of the milled samples were processed in the same milling direction.

All three samples (A, B and C) were treated by MHP using the same parameters. For the two face milled specimens ( $\mathrm{B}$ and $\mathrm{C}$ ), different peening directions were applied. For specimen B the direction was chosen normal to the direction of the milling step. For specimen $\mathrm{C}$, the peening direction coincided with the milling direction. An overview of these different process directions is illustrated in "Fig. 7".

After the MHP treatment, the residual stresses were investigated at each sample with the methods mentioned in chapter 3. . The results are compared in the next following.

\subsection{Results}

The stress measurements were done in two directions ("horizontal" and "vertical" according to "Fig. 7") for the references as well as the Machine Hammer Peened surfaces. The content of "Fig. 7".(especially of the different measurement directions) can be directly compared with the results in "Fig. 8".

Both measurement methods show a significant induction of compressive residual stresses in the work piece surface up to a maximum of approximately $700 \mathrm{MPa}$. At all three specimens, the X-Ray diffraction measurements and the results of the hole drilling method are in good agreement. The range of scatter of approximately $\pm 200 \mathrm{MPa}$ for the hole drilling method and the standard deviation for the X-Ray diffraction method have to be taken into consideration, however, when interpreting the data.
Furthermore, the investigations show that, at specimen $\mathrm{B}$, a maximum compressive residual stress value of approximately $-650 \mathrm{MPa}( \pm 200 \mathrm{MPa})$ prevails in the horizontal measuring direction, which is normal to the peening feed direction. In the vertical measuring direction, the data shows less compressive residual stress of maximum $-350 \mathrm{MPa}( \pm 200 \mathrm{MPa})$. This direction is parallel regarding to the Machine Hammer Peening feed direction.

The investigation of specimen $\mathrm{C}$ is showing a similar result. A higher compressive residual stress value of maximum $-650 \mathrm{MPa}( \pm 200 \mathrm{MPa})$ could be induced in the vertical measuring direction, which is normal to the MHP direction for this sample. Compared to this, the value of $300 \mathrm{MPa}( \pm 200 \mathrm{MPa})$ for the horizontal measuring direction is much lower.

From the hole drilling residual stress measurement, we observe the expected residual stress profile predicted from Hertz's compression[6]. In the hole drilling method, stress data is delivered as a function of depth, in contrast to X-ray diffraction, which gives information on the very surface area of the specimen.

From our data, we conclude that the Machine Hammer Peening feed direction has a direct impact on the induction of compressive residual stresses in the material C45E (1.1191). Normal to the peening direction, the values for the induced compressive residual stresses are higher. A directional induction of compressive residual stresses is, therefore, possible with this technology. These findings could be confirmed by both residual stress measurement methods, hole drilling and X-Ray diffraction.

\section{HARDENING OF THE UPPER SURFACE LAYER}

The second main topic of this paper is the upper surface layer hardening.

\subsection{Measuring Method}

The UCI hardness test is a dynamic test method, which is based on the principle of ultrasonic contact impedance. With this method, a static force is applied to produce a small indentation. The contact area can then be determined by measuring the change in the resonant frequency of the vibrating intender.

\begin{tabular}{|l|c|c|c|}
\hline \multirow{2}{*}{} & \multicolumn{3}{|c|}{ Specimens } \\
\cline { 2 - 4 } & $\boldsymbol{A}$ & $\boldsymbol{B}$ & $\boldsymbol{C}$ \\
\hline Material & $\begin{array}{c}\text { C45E } \\
(1.1191)\end{array}$ & $\begin{array}{c}\text { C45E } \\
(1.1191)\end{array}$ & $\begin{array}{c}\text { C45E } \\
(1.1191)\end{array}$ \\
\hline $\begin{array}{l}\text { Pre-processing before } \\
\text { MHP }\end{array}$ & Normalized & Milled $\uparrow$ & $\begin{array}{c}\text { Milled } \\
\rightarrow\end{array}$ \\
\hline MHP Diameter D [mm] & 8 & 8 & 8 \\
\hline MHP Distance t [mm] & 1 & 1 & 1 \\
\hline $\begin{array}{l}\text { MHP Line pitch s [mm] } \\
\text { MHP Feed ratev }\end{array}$ & 0,2 & 0,2 & 0,2 \\
\hline mm/min] & 2400 & 2400 & 2400 \\
\hline
\end{tabular}

Tab. 3. Residual stress investigations of Machine Hammer Peened surfaces 


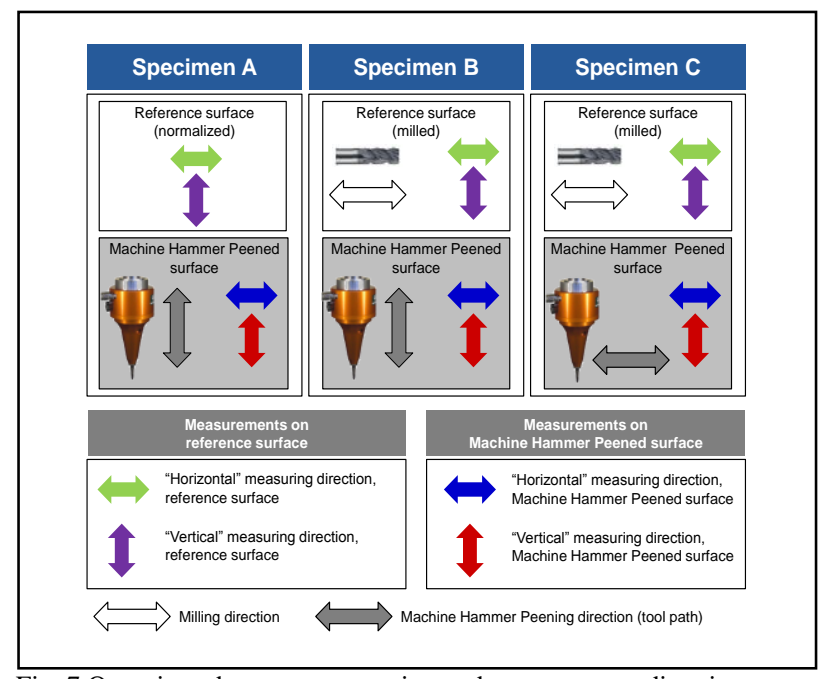

Fig. 7.Overview about pre-processing and measurement directions

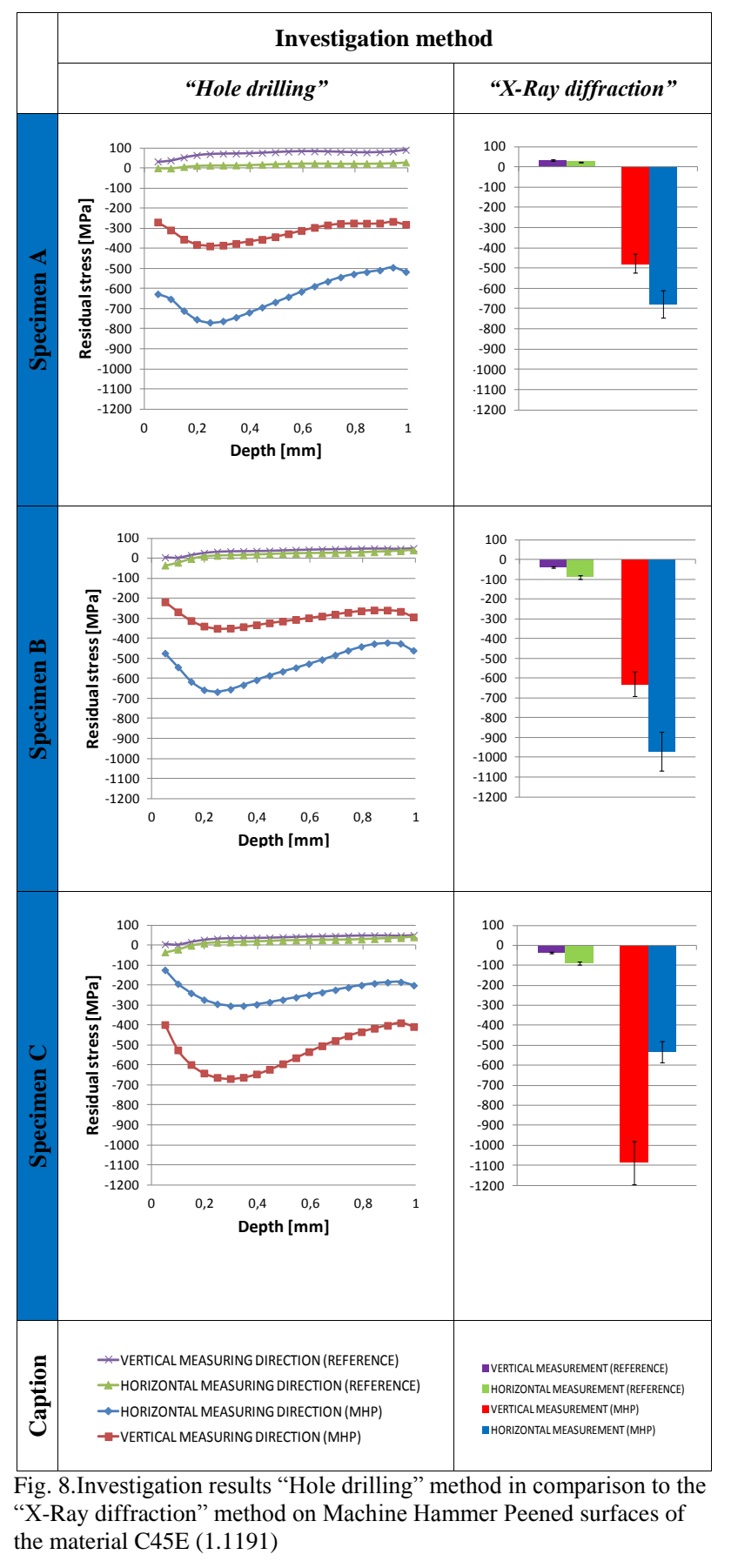

The frequency change $\Delta f$ depends on the elasticity modulus $\left(E_{\text {eff }}\right)$ and the size ofthe contact area $(A)$ between the Vickers intender and the sample surface [9].

$$
\Delta f=f\left(E_{e f f}, A\right)
$$

The change in the resonant frequency corresponds to the hardness at the surface.

For the investigations in this paper, the UCI device Microdur II from Krautkrämer Branson with a $136^{\circ}$ diamond pyramid (diagonal $15 \mu \mathrm{m}$ ) was used. The load for the investigations was chosen to be $150 \mathrm{~g}$.

\subsection{Experimental work}

In order to study the influence of the peening distance $t$ on the increase of hardness, the following investigation was performed. A milled surface of C45E (1.1191) steel material was modified by MHP using the parameter setting given in Tab. 2. Then, $t$ was varied in a range of $0,3 \mathrm{~mm}$ to $1,2 \mathrm{~mm}$ in $0,2 \mathrm{~mm}$ steps for the machining of different test fields.

The measuring for each field was done on nine different positions, see "Fig. 9". In "Fig. 10", the results are presented as the average value of these single measurements with the according standard error visualized as error bars.

\subsection{Results}

The results of the UCI investigation show an increase of hardness in the upper surface layer for all hammer peened surfaces. A maximum increase of approximately $15 \%$ compared to the milled reference surface could be achieved with the MHP technology on the investigated material C45E (1.1191). The dependency of the hardness values from the peening distances $t$ is depicted in "Fig.8".

In further investigations using other test materials, the suitability of MHP surface treatment to increase the materials hardness could be shown. During these investigations, the materials: $\mathrm{C} 45 \mathrm{E}, \mathrm{C} 45 \mathrm{E}$ hardened, X155CrVMo 121 , X155CrVMo 121 hardened, X3CrNiMo13 4 (1.4313), P550, P670 and CuZn39Pb2-3. were modified by MHP.

An overview about the maximum reachable surface hardness increase in percent compared to the original Vickers hardness of the reference sample is given in Tab. 4. In all cases, the hardness of the milled reference sample could be increased by MHP.

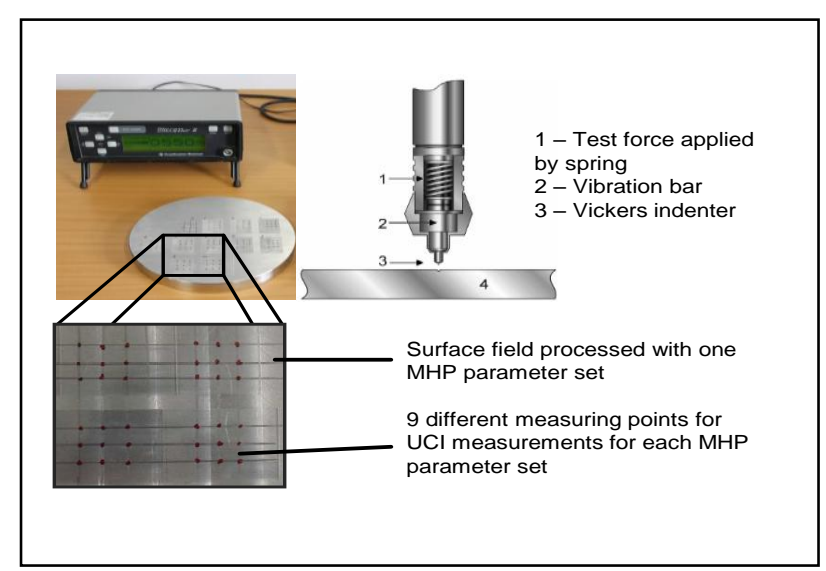

Fig. 9. Principle of the UCI hardness test method [10] 


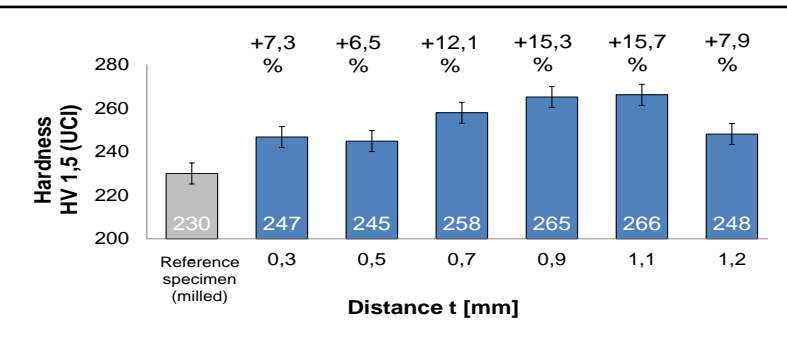

Fig. 10. Hardness increase of the upper surface layer of surfaces modified with MHP (UCI measurements)

\begin{tabular}{|c|c|c|c|c|}
\hline & \multirow[b]{2}{*}{$\begin{array}{l}\text { Investigated } \\
\text { materials } \\
\text { (overview) }\end{array}$} & \multicolumn{3}{|c|}{ Material properties } \\
\hline & & ฐ ฐ & 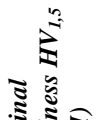 & 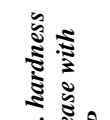 \\
\hline 1 & $\mathrm{C} 45 \mathrm{E}$ & 1.1191 & 241 & $+12,0 \%$ \\
\hline 2 & $\begin{array}{l}\mathrm{C} 45 \mathrm{E} \\
\text { hardened }\end{array}$ & 1.1191 & 527 & $+9,9 \%$ \\
\hline 3 & X155CrVMo 121 & 1.2379 & 266 & $+13,5 \%$ \\
\hline 4 & $\begin{array}{l}\text { X155CrVMo } 121 \\
\text { hardened }\end{array}$ & 1.2379 & 528 & $+14,6 \%$ \\
\hline 5 & $\begin{array}{l}\text { X3CrNi } 134 \\
\text { normal }\end{array}$ & 1.4313 & 292 & $+8,8 \%$ \\
\hline 6 & P550 & - & 439 & $+20,0 \%$ \\
\hline 7 & P670 & - & 481 & $+16,0 \%$ \\
\hline 8 & $\mathrm{CuZn39Pb2-3}$ & 2.0181 & 127 & $+83,9 \%$ \\
\hline
\end{tabular}

Tab. 4. Overview of the hardness increase for different materials and pre-processing

\section{CONCLUSION}

On the example of the steel C45E,the investigations described in this paperclearly demonstrate the potential of MHP to induce compressive residual stresses and increased hardness into the upper surface layer of metallic materials. The hammering process produced compressive residual stress, approximately up to -700 $\mathrm{MPa}$. The comparison of the hole drilling method and the X-Ray diffraction method showed a good qualitative agreement within the range of uncertainty of the measuring techniques. Also, the directional effect for the induction of compressive residual stresses could be quantified and it is reported in this paper.

In addition to the induction of residual stresses, the upper surface layeris hardened by MHP. The hardness of the material C45E (1.1191)was increased by approximately $15 \%$ in comparison to the milled reference sample. A hardness increase in the upper surface layer could also be detected for the materials: C45E, C45E hardened, X155CrVMo 12 1, X155CrVMo 121 hardened, X3CrNiMo13 4 (1.4313), P550, P670 and $\mathrm{CuZn} 39 \mathrm{~Pb} 2-3$. The focus of further research will be set on the investigation of different work piece materials and to quantify their hardening and residual stress potential.

\section{ACKNOWLEDGEMENTS}

This work was funded from the Austrian COMETProgram and has been carried out within the "Institute of Materials Science and Technology", "Institute for Production Engineering and Laser Technology" and "Institute for Energy Systems and Thermodynamics" in cooperation with the Excellence Centre of Tribology".

The authors thank the following companies for their support in the mentioned research project (in alphabetical order): "ANDRITZ HYDRO GmbH", "EMO ORODJARNA proizvodna Druzbad.o.o.", "Flowserve Austria GmbH", "KWL -Konstruktion \& Werkzeugbau Löcker", "Maschinenfabrik Berthold Hermle AG", "SchoellerBleckmann Oilfield Technology GesmbH", "TIWAG TirolerWasserkraft AG", "VERBUND AG", "Voith Hydro GmbH \& Co KG", "VorarlbergerIllwerke AG" and "Wittner Ernst GmbH".

\section{REFERENCES}

[1] http://accurapuls.de Accessed: 2012-06-01

[2] Bleicher, F.; Lechner, C.; Habersohn, C.; Kozeschnik, E.; Adjassoho, B. \& Kaminski, H. (2012). Mechanism of surface modification using Machine Hammer Peening technology, CIRP Annals - Manufacturing Technology, Vol. 61, No. 1, pp. 375-378

[3] Wied, J. (2006). Machine polishing of Metal Forming Dies, Master's theses, Royal Institute of Technology, Stockholm Sweden

[4] Wied, J. (2011). Oberflächenbehandlung von Umformwerkzeugen durch Festklopfen, Ph.D. Dissertation, Technical University of Darmstadt, Darmstadt, Germany

[5] Berglund, J.; Liljengren, M. \& Rosén, B.-G. (2011). On finishing of pressing die surfaces using Machine Hammer Peening, International Journal of Advanced Manufacturing Technology, Vol. 52, 2011, pp. 115-121

[6] Kritzler, J. and Wübbenhorst W. (2002). Inducing Compressive Stresses through Controlled Shot Peening, Handbook of Residual Stress and Deformation of Steel, pp. 345-358

[7] Prevéy, S. P. (1986). X-ray Diffraction Residual Stress Techniques, Metals Handbook, 10, pp. 380-392

[8] Prevéy, S. P. (1996). Current Application of X-ray Diffraction.Residual Stress Measurement. Developments in Materials Characterization Technologies, ASM International, pp 103-110

[9] Nobre, J.P.; Dias, A.M. Dias; Gibmeier, J and Kornmeier, M. (2006). Local Stress-Ration Criterion for Incremental HoleDrilling Measurements of Shot-Peening Stresses. Jornal of Engineering Materials and Technology, Vol 128, pp.193-201

[10] Herrmann, K. (2007). New developments and application in hardness metrology. Recent Advancement of Theory and Practice in Hardness Measurement, pp. 1-1

[11] http: //mts3000.com Accessed: 2012-02-06 